\title{
2 Gender implications of COVID-19 in Cambodia
}

\author{
Sovanneary Huot and Leif Jensen
}

The COVID-19 pandemic threatens the health and economy of all countries - large and small, rich and poor. Although the Cambodian government successfully averted widespread virus transmission in 2020, it has recently seen a spike in confirmed cases and deaths. COVID-19 poses the greatest challenge to the health and well-being of the Cambodian community, education system, and key engines of Cambodia's economy - garment, textiles, and footwear (GTF) manufacturing, tourism, construction, and agriculture. School closures profoundly impacted learning and assessment systems. About 39 percent of paid workers have been severely affected (World Bank 2020a). Lockdowns and social distancing restrictions broke the links between farmers and their markets, resulting in income loss. Rapid income decline creates panic and jeopardizes food security for vulnerable groups, including people with disabilities, children, migrant workers, older people, and woman-headed households. Here we focus on COVID-19's impacts on food security, consumption, and gender differences, especially among smallholder farmers. We first describe Cambodia's COVID-19 experience, then detail impacts of the pandemic on education, the garment industry, construction, tourism, and agriculture. Finally, we consider the government response to the pandemic.

\section{COVID-19 in Cambodia}

Cambodia's experience with COVID-19 has been dynamic. Immediately after a spike in March and April 2020, the government created the National Committee for COVID-19 Response, led by the Prime Minister, implementing school, business, and factory closures; international and domestic travel restrictions; mass gathering bans; social distancing; and mask mandates. The government collaborated with the Pasteur Institute in Cambodia, the World Health Organization (WHO), and the US Centers for Disease Control and Prevention to develop screening, tracing, testing, quarantine, and treatment to 
limit virus transmission. The Khmer New Year holiday and the Water Festival were cancelled. As the infection rate declined during the third and fourth quarters of 2020, some restrictions were lifted, and limited economic activity in agriculture, manufacturing, and other sectors resumed. Public and private institutions and schools partially or fully reopened. Initial success reversed in spring 2021 with a spike in cases. The new B.1.1.7 variant spread quickly. As a result, although Cambodia reported relatively few cases in 2020, it is now catching up with its neighbors, with 2,378 cases and 11 deaths by March 30, 2021. Economic activity was curtailed anew, and all schools were ordered to fully close again on March 20,2021. Although vaccinations began, only 401,972 vaccine doses had been administered by March 23, 2021.

\section{Impacts on education}

School closures profoundly impacted the education system, millions of students, and thousands of teachers and schools (MoEYS 2020). Standard learning systems and assessment forms were interrupted, with significant impacts on learning quality and human capital growth (World Bank 2020a). Digital education systems adopted to mitigate COVID-19 risk reach only the 20 percent of students with Internet access (CARE 2020). Unequal access to online learning materials disadvantages rural and economically vulnerable families. Mindful of such disparities, the Ministry of Education, Youth, and Sport (MoEYS 2020) delivered various forms of distance learning programs - via social media platforms, television, and radio - to keep kids learning during this unprecedented period.

There is a widening gender gap in access to education. Girls from rural and low-income families are at risk of having fewer opportunities to access school materials or return to school upon reopening. Some families experiencing economic hardship keep girls at home to help with household chores and childcare. Women bear a disproportionate burden from school closures with new care responsibilities for now out-of-school children and home schooling (UN 2020).

A school feeding program ${ }^{1}$ in ten provinces also closed. During the first school closures, the World Feeding Program (WFP) partially continued with take-home meals to school children from the poorest households. When schools partially reopened, the program resumed but was threatened by the surge in cases.

\section{Impacts of industry closures on income, remittances, and food security}

GTF manufacturing, tourism, and construction were adversely affected (World Bank 2020b). Income and remittances declined, placing additional 
pressure on families, exacerbating declines in farm income and risks of food insecurity (Oxfam 2020). Factory and business closures compelled many migrant workers to return home, increasing household expenses. As of 2019, approximately 4.1 million rural individuals out-migrate for work annually, the majority to Phnom Penh's garment factories. Women outnumber men; young women comprise more than 80 percent of the GTF workforce. In addition to domestic labor migration, 2.5 million Cambodians live abroad, including 1.2 million Cambodian workers in Thailand. The pandemic left tens of thousands of migrant workers unemployed, eliminating overnight the remittances that keep many rural households afloat (ADB 2020). The unprecedented closures of workplaces in Thailand and the ThaiCambodia border led to massive return migration. The government collaborated with the UN Joint Program ${ }^{2}$ to protect migrant-sending communities from the virus by providing COVID-19 prevention information and health care services. Additionally, the program helped returned migrants cope with socioeconomic impacts. Vulnerable individuals, particularly women and woman-headed households, received economic reintegration packages, including grants for setting up small businesses, grocery stores, livestock raising, and other income-generating activities (IOM Cambodia 2020).

International travel restrictions and local lockdowns resulted in a collapse of tourism and hospitality services, causing around 11,000 tourism workers to lose their jobs (UN 2020). Closures of restaurants, tourist destinations, and businesses reduced food purchasing and demand for farm production. As reported by the UNDP Cambodia, Ms. Soda, deputy chief of Sovatepheap Thoamacheat Agricultural Cooperative, observed that

[b]efore COVID-19, we faced a supply shortage - we had access to markets but not enough vegetables. After COVID-19, it is the opposite: workers return [from the towns and cities] and begin to grow vegetables, but there are not enough buyers [due to reduced demand from restaurants, tourists etc.], so we then have a market surplus.

Members of this cooperative have had to settle for lower prices (UNDP Cambodia 2020).

\section{Impacts on agriculture and smallholder farmers}

The pandemic's effects on agriculture extend well beyond production for the devastated tourism industry. To ensure sufficient food for the population and avert high food prices, Cambodia's government, in April 2020, declared a ban on certain exports that has since been lifted. Social distancing restrictions and fear of the virus imposed additional constraints on smallholder 
farmers. Limited ability to sell their farm products led to decreased incomes (UN 2020). A study by Future Forum \& Angkor Research (2020) indicates that smallholders in Siem Reap, Kampong Speu, and Kampot provinces saw painful income declines by 46,46 , and 29 percent, respectively. Income from selling vegetables, fruits, and aquaculture decreased by 32,95 , and 46 percent. Fortunately, income from selling paddy rice increased by 51 percent. Food purchasing patterns shifted toward staple foods over vegetables and fruits, reflecting heightened priority on household food security.

The COVID-19 pandemic has reinforced gender inequalities (Oxfam Cambodia 2020). Smallholder women farmers already have limited access to productive resources, services, technologies, markets, and investment capital and are more vulnerable to income loss (ADB 2020). Business and service closures increase the difficulty of selling their products, since women have limited access to markets and transportation compared to men. Weak demand for diverse crops forces women smallholders to sell their goods at lower prices. The income loss challenges continuation, not to mention expansion of their farming enterprises. To gain a comprehensive understanding of the hardships faced by women smallholder farmers, the lead author remotely interviewed farmers affiliated with the Women in Agriculture Network Project in Cambodia (WAgN-Cambodia). ${ }^{3}$ A woman farmer of an agricultural cooperative (KKSRAC) in Siem Reap province reported that her family was severely affected by COVID-19. In the lockdown her husband and adult children lost their jobs. The closures led to an estimated 30-40 percent decrease in demand for her vegetables, a penalty worsened by lower prices for what she could sell (Figure 2.1).

Other women farmers in Battambang Province reported similar challenges and hardships. They sold their vegetables at a lower price and, consequently, lacked investment capital for the next growing season. A women farmer in Battambang lamented, "I felt really discouraged by the drop in prices we could get for whatever vegetables we have grown." They used to have several sources of income, including vegetable sales and remittances. Since the lockdown, their husbands and children returned home causing income losses and added expenses for food, medical care, and other household expenditures, simultaneously increasing care work for women (Figure 2.2).

Income decline decreases food security for vulnerable groups. A household survey found coping mechanisms among Cambodians experiencing income loss include reducing food and non-food consumption, buying food on credit, and borrowing from relatives and friends (Karamba et al. 2020). Elders are adversely affected, with 61 percent eating less food or consuming poorer quality food (HelpAge International 2020). Woman-headed households have experienced a higher rate of food insecurity during the 


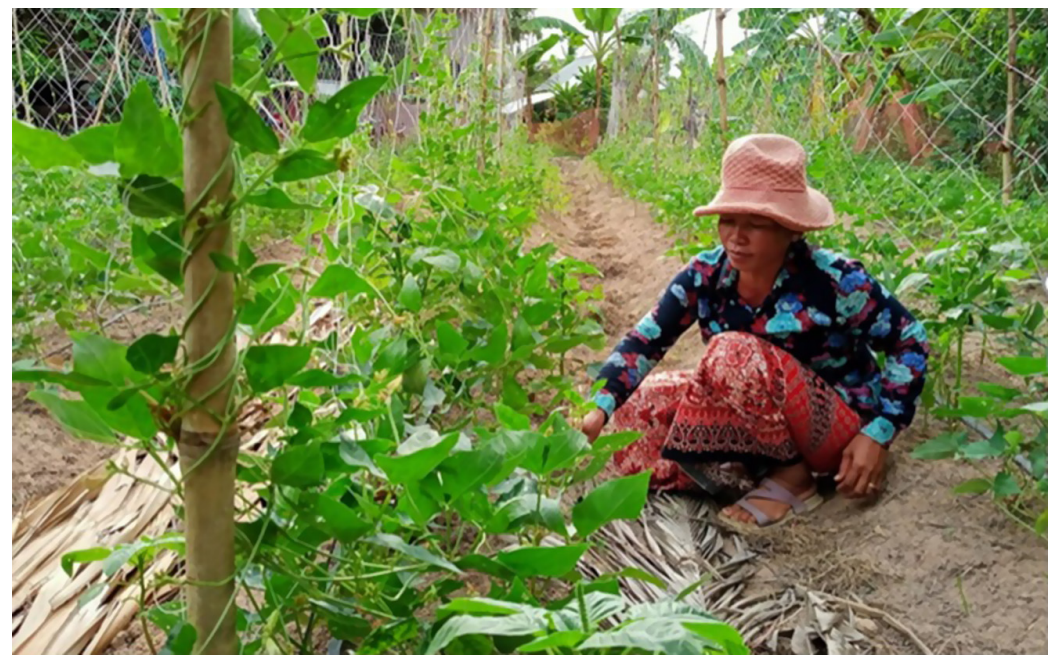

Figure 2.1 A Cambodian woman farmer. Smallholders have been especially hard hit by the pandemic (Phang Saret).

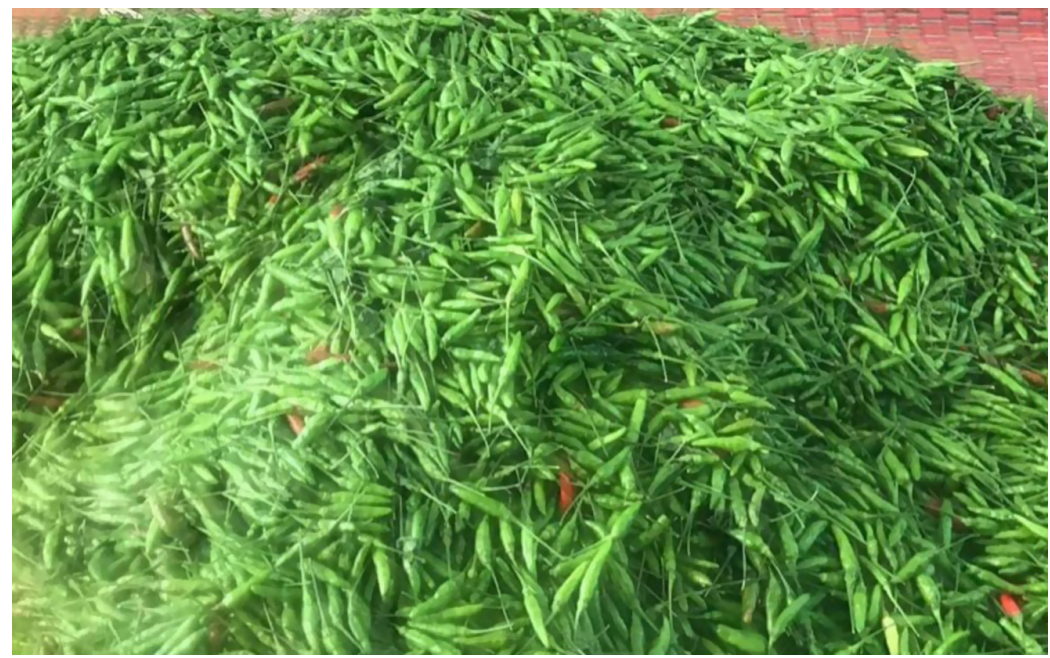

Figure 2.2 Chilis from a woman's farm in Battambang Province. Despite a reduced price, she finds it hard to sell them (Channaty Ngang). 
pandemic than man-headed households. Over one-third of woman-headed households have faced moderate food insecurity compared to less than onequarter among man-headed households (Future Forum \& Angkor Research 2020). If prolonged, food insecurity and diets insufficient in micronutrients threaten the cognitive development of hundreds of thousands of children (UN 2020). The pandemic also heightened women's vulnerability to climate change. Notably, a massive flash flood occurred in October 2020 destroying thousands of homes and hectares of agricultural land. Negative impacts on shelter, agricultural production, food stocks and seed availability exacerbated already disadvantaged women's vulnerabilities (HRF 2021; ADB 2020). Reduced incomes mean less money for an adequate diet (HRF 2021).

\section{Government response}

The Cambodian government has taken some economic recovery measures, including reducing taxes, restructuring loans, and providing investment capital at low interest rates for small-, medium-, and large-sized farms, enterprises, or businesses. Intended to help farmers maintain production, small-scale farmers are less likely to benefit, often having less access to these loans compared to larger farms. For livelihood coping assistance, the government provided stimulus funds to 2.4 million poor and vulnerable households (UN 2020). Gender is not considered among eligibility criteria for this support; all registered poor and vulnerable households are entitled. However, the government offered additional support to pregnant women from impoverished households, hoping to reduce maternal and infant malnutrition. While some farmers would have qualified for the stimulus package funds, that program was more for emergency food relief based on their low income. It was not designed to help poor smallholders sustain their farms. The government has also taken social protection measures to support factory workers and tourism-related service workers temporarily laid off. A US $\$ 40$ per month stimulus was provided to tourism-related service workers, while US $\$ 70$ per month (US $\$ 40$ from the government, US $\$ 30$ by factory owners) was provided to factory workers (UN 2020). The coping assistance and social protection supports lasted from May to December 2020.

These programs only target poor households, formal sector workers, medium- and large-sized farms, or enterprises, excluding informal workers. Approximately 6.1 million informal workers (including smallholder farmers) have suffered from the pandemic but cannot benefit from the government's cash support (CARE 2020). An example is Srey Touch, a married woman with two small children, who lost her job as an entertainment worker when the virus hit, making her family homeless (Oxfam Cambodia 
2021). A victim of domestic abuse and abandonment by her husband, she fought to survive by joining with other coworkers in filing for the government's National Social Security Fund. Unfortunately, their applications were denied given their status as informal workers. Things became more hopeful when Srey Touch joined the Cambodian Food and Service Workers Federation (CFSWF), which provides training in women's rights and gender equality. She empowered herself and worked to protect, support, and empower other women in the informal sector to acquire their rights. She now has proper shelter and enough nutritious food for her children. In her words:

I have received a lot of new knowledge from various training by CFSWF. I've learnt about women's rights, gender-based violence, and social protection. It provides me a concrete foundation to speak up for my right as a woman and worker. I'm happy that I can use this knowledge to support other coworkers who are working in the entertainment sector like me.

In sum, the pandemic has profoundly disrupted all aspects of Cambodian life, including but not limited to economic opportunity, food security, time poverty, and social and psychological well-being. It has laid bare and exacerbated prevailing gender-based inequalities. Smallholder farmers have been severely affected by social distancing restrictions, while women smallholder farmers have faced greater challenges and more vulnerabilities to the socioeconomic crisis than their male counterparts.

\section{Notes}

1 WFP provided free meals to 280,000 school children in 1,113 pre-primary and primary schools across ten provinces in 2020.

2 The UN Joint Program in Cambodia was created by four agencies - WHO, UNFPA, UNICEF, and IOM - and funded by the COVID-19 Multi Partner Trust Fund (MPTF).

3 The WAgN-Cambodia project was designed by Penn State University researchers and partners to empower women and improve the nutrition status of women and children in Cambodia with support from the USAID-funded Sustainable Intensification Innovation Lab (SIIL) at Kansas State University. Both authors were part of this project.

\section{References}

ADB 2020. Proposed countercyclical support facility loan Kingdom of Cambodia: COVID-19 active response and expenditure support program [online]. Available 
from: COVID-19 Active Response and Expenditure Support Program: Report and Recommendation of the President (adb.org) [accessed 25 July, 2020].

CARE 2020. Rapid gender analysis during COVID-19 pandemic, mekong subregional report Cambodia, Lao People's Democratic Republic, Myanmar, Thailand and Viet Nam [online]. Available from: Regional-Mekong-Rapid-Gen der-Analysis_COVID-19_Final_September2020.pdf (reliefweb.int) [accessed 17 October 2020].

FAO 2020a. COVID-19 and smallholder producers' access to markets. Rome: FAO. doi:10.4060/ca8657en.

Future Forum \& Angkor Research 2020. Covid-19 gender analysis at the household and wage worker level [online]. Available from: Publications (angkorresearch.c om) [accessed 25 July, 2020].

HelpAge International 2020. COVID-19 rapid needs assessment of older people July 2020 [online]. Available from: covid19-rapid-needs-assessment--asia-pac ific--region.pdf (helpage.org) [accessed 15 March, 2021].

HRF 2021. Floods response plan: Cambodia [online]. Available from: PowerPoint Presentation (reliefweb.int) [accessed 27 February, 2021].

IOM Cambodia 2020. COVID-19 response: Situation report [online]. Available from: C: $\backslash$ Users $\backslash$ MWALKO $1 \backslash$ AppData $\backslash$ Local $\backslash$ Temp $\backslash$ mso936A.tmp (iom.int) [accessed 28 January, 2021].

Karamba, W., Nkengene, C.T., and Tong, K. 2020. The socioeconomic impacts of COVID-19 on households in Cambodia. The high-frequency phone survey of households round 1. World Bank Group [online]. Available from World Bank Document [accessed 25 March, 2021].

MoEYS 2020. Cambodia education response plan to COVID 19 pandemic. $\mathrm{Phnom}$ Penh, Cambodia [online]. Available from: Cambodia Education Response Plan to COVID-19 Pandemic July 2020 (moeys.gov.kh) [accessed 25 July, 2020].

Oxfam Cambodia 2020. The impact of COVID-19 on Cambodia's most vulnerable populations [online]. Available from: Oxfam_Brief - The impact of Covid-19 LV06 (oi-files-cng-prod.s3.amazonaws.com) [accessed 15 March, 2021].

Oxfam Cambodia 2021. A Women's struggle with COVID-19: on story of survival, strength and hope [online]. Available from: A Woman's Struggle with Covid19: a Story of Survival, Strength and Hope | Oxfam in Cambodia [accessed 15 March, 2021].

UNDP Cambodia 2020. Living in rural Cambodia during COVID-19: Examples from farming communities [online]. Available from: Living in Rural Cambodia during COVID-19: Examples from Farming Communities | UNDP in Cambodia [accessed 27 February, 2021].

UN 2020. UN Cambodia framework for the immediate socio-economic response to COVID-19 [online]. Available from: KHM_Socioeconomic_Response-Plan _2020.pdf(un.org) [accessed 27 February, 2021].

Oxfam Cambodia 2020. The impact of COVID-19 on Cambodia's most vulnerable populations [online]. Available from: Oxfam_Brief - The impact of Covid-19 LV06 (oi-files-cng-prod.s3.amazonaws.com) [accessed 15 March, 2021].

Oxfam Cambodia 2021. A Women's struggle with COVID-19: on story of survival, strength and hope [online]. Available from: A Woman's Struggle with Covid-19: 
Gender implications of COVID-19 in Cambodia 21

a Story of Survival, Strength and Hope | Oxfam in Cambodia [accessed 15 March, 2021].

WHO 2021. WHO Coronavirus (COVID-19) dashboard [online]. Available from: Cambodia: WHO Coronavirus Disease (COVID-19) Dashboard | WHO Coronavirus Disease (COVID-19) Dashboard [accessed 25 March, 2021].

World Bank 2020a. Cambodian economic update: Cambodia in the time of COVID19. Washington, DC: World Bank Group.

World Bank 2020b. Cambodian economic update: Restrained Recovery. Washington, DC: World Bank Group.

WFP Cambodia 2021. Cambodia country brief February 2021. [online]. Available from: https://docs.wfp.org/api/documents/WFP-0000125049/download/?_ga $=2.92684445 .1426877709 .1616617611-1170571446.1611447354$ [accessed 15 March 2021]. 